\title{
The Imperfection in a Firm's Knowledge of the Transformation Process Among Interlinked Internal Networks: The Defect Case
}

\author{
Cris Kuntadi ${ }^{*}$, Prasetyo Boeditjahjono ${ }^{b}$, Yuli Permatasari, Meylia Candrawati ${ }^{l}$ \\ Indonesian Railways Company, University of Mercubuana, Indonesia \\ ${ }^{\mathrm{b}}$ Ministry of Transportation, Indonesia \\ 'STIE Nobel Indonesia, Indonesia \\ ¿PT. Telkom Indonesia, Indonesia
}

\begin{abstract}
This study, firstly, identifies and analyzes the supply chain management of Aseli Dagadu Djokdja, Co., Ltd., (here-after ADD) which has a problem. Secondly, this study pinpoints what causes the problem in ADD's supply-chain management (SCM). Thirdly, it investigates ADD's knowledge of the transformation process, since it was not conducted properly. This research chose to use an exploratory case study with an in-depth interview to collect the data. This article questions all the CEOs and observes all stages of activity accompanied by their information, resources, and financial flows. The interviewer applies angulations to two or more of the subjects. This study takes note that ADD's knowledge of the transformation process is imperfect; this weakness is at the top managerial level. The problem is also found when oral explanations do not follow the transfer of documents among the divisions and staff. It means that information asymmetry takes place. This study, which is designed with SNT and a comprehensive knowledge of the transformation process, has several biases. The first one is the inference validity bias. Secondly, it did not investigate how ADD's management faces industrial competitiveness. Finally, this research could not capture what the staff at ADD transforms their knowledge into.
\end{abstract}

Keywords: knowledge, transformation process, diffusion, innovation, social networks

JEL Classification: D83

The authors would like to convey our gratitude to any critics and for comments and suggestions from all the seminars' participants. The authors' emails are: cris.kuntadi@mercubuana.ac.id; prasetyoboeditjahjono@gmail.com; yulipermatasariamir@gmail.com and meyliacandrawati@ gmail.com (as corrsponding author

*Corresponding author's e-mail: cris.kuntadi@mercubuana.ac.id ISSN: PRINT 1411-1128 | ONLINE 2338-7238 http://journal.ugm.ac.id/gamaijb 


\section{Introduction}

This article highlights the problems small and medium enterprises (Hosmer) have in engaging with their supply chain management (SCM). Wieland, Handfield, and Durach (2016) and Turban, Bolloju, and Liang, (2010) suggested that a firm could achieve relative benefits when it could implement its SCM correctly. The supply chain describes how firms manage their material, information, and financial flows, especially from the perspective of their input and output. Kwon, Kim, and Martin (2016) and Levallet and Chan (2019) suggested that firms have problems understanding the principles behind SCM, and this causes them to attempt to fix their problems without having the optimal solutions. The failure to understand the needs of its SCM is ADD's biggest problem. This failure resulted in $39.08 \%$ of ADD's orders experiencing production delays in 2016. These delays made the customers feel unhappy, because the company could not produce everything it was contracted to do in the required time limit. Therefore, this article investigates the questions below. First, how does ADD's SCM work? Second, why do production delays occur? Third, why was the knowledge of the transformation process not managed appropriately? Fourth, did information asymmetries occur among the different departments? Fifth, why does ADD's top management not empower its middle and lower management to collaborate internally?

This case is challenging because of the following critical reasoning. First, this article elaborates on the underlying problem through the social network theory (SNT) and knowledge of the transformation process. This study chose to use these theories because of ADD's situation i.e. the existence of internal and external functions in its organizational structure. However, there is the probability of defects being present in its knowledge of the transformation process among its various divisions. This phenomenon causes delays in its production schedule and in the fulfillment of its sales orders. Ouchi $(1977,1979)$ argued that when managers' knowledge of the transformation process is imperfect (i.e., their understanding of meansends relationships in activities is poor), they control their subordinates' behavior by using the clan approach. Mitchell (1974) explained that the SNT, as a theoretical construct, functions by relating to individuals, or groups that have specific characteristics, protected by norms and supported by each individual's trust. Moreover, social networks are created because of knowledge of the transformation process among their members. Therefore, ADD could not control the inter-division relationships from the combination of SNT and knowledge of the transformation process.

Second, this study takes ADD as a leading case. This case argues that ADD is a well known manufacturing firm, and probably the best one in Yogyakarta. The World Bank proposed Yogyakarta as the most eligible place for start-up businesses. Besides, Yogyakarta was named as the best policy creator by the International Council for Small Business (ICSB), Indonesia, which was well-known as Presidential Award 2017. It means that Yogyakarta is the most suitable region for SMEs to establish themselves and then expand nationally.

Third, this study investigates this phenomenon using an organizational unit analysis. Therefore, this study takes the informants from all CEOs, who are the heads of human resources, production and planning, purchasing, and administration and accounting. It could elaborate on the critical reasoning perceived by all the CEOs. They disclose how ADD's SCM works, and why the pro- 
duction delays occur. However, this study limits its use of the various contexts in the SNT and the knowledge of the transformation process. It means that both the informants' and the study's contexts could reveal their reasoning for the weaknesses, flaws, limitations, or powerlessness of ADD's SCM.

This study uses the social networking theory (SNT) (Turban et al., 2010; Wasserman and Faust, 1994) and knowledge of the transformation process (Ouchi, 1977, 1979) to elaborate ADD's problem. The SNT(Turban et al., 2010) suggested that the relationship between inter-individuals, groups, or divisions usually has individual characteristics, although they are in unity. This case, therefore, captures the failure of ADD's SCM and analyzes how and why it occurred. Secondly, this study employs its knowledge of the transformation process (Ouchi, 1977, 1979) to identify whether information that enters ADD is disseminated simultaneously or sequentially to the employees, or not. From other perspectives, this study investigates whether the existence and occurrence of information asymmetry are present among the divisions in ADD. Finally, this study combines the SNT and knowledge of the transformation process to identify the information that could not flow correctly from department to department in ADD.

This study expects to disclose the critical reasoning for why ADD had faults in its SCM implementation, and why they occurred. This article highlights that big firms sometimes fail to implement their SCM, and how small firms can implement it even with constraints on their resources. By managing its SCM optimally, a firm could get some benefits that are always aligned with its mission. Beatriz, Alceu, Adriana, and Charbel (2011) and Bloodgood (2019) explained that SCM is the most effec- tive tool to improve a firm's performance. Therefore, a firm could improve its performance when it has an organizational structure that allows the SCM to function well. Moreover, it must also perform knowledge of the transformation process among its divisions so that there is no information asymmetry. Practically, a firm usually has well-organised plans for the materials, inventory, capacity, labor, machinery, and other things it needs to ensure a smooth production process.

This study has six sections. Section 2 presents the company background. Section 3 presents the case study method. Section 4 discusses an in-depth review of the extant literature, leading to the identification of critical constructs, findings, and managerial implications. Section 5 presents the conclusion and limitations as well as the possible future research.

\section{Company Background}

Aseli Dagadu Djokdja, Co., Ltd. (Al-Haddad) is a manufacturing firm producing some of the souvenirs sold in Yogyakarta. ADD is a prominent and well known company, established on January 4th, 1994, and has produced alternative souvenirs with the theme, "Everything about Djokdja." Dagadu's name was chosen from the Jogjanese slang language, "dagadu" means "matamu" (English: crash-you). To maintain local values, the founder added the word "Djokja" after the word dagadu. Meanwhile, the old spelling of "Djokja" is meant to give a traditional sense of the City of Yogyakarta. Currently, Dagadu Djokja has three official outlets, and one headquarters building to market its products, namely Posyandu, which is located on the lower ground floor of Malioboro Mall. Posyandu 2 is located at Jl. Pekapalan No. 7, in Alun-Alun Utara, and Yogyatorium is on Jl. Gedongkuning Sela- 
Gadjah Mada International Journal of Business - Jan.-April, Vol. 22, No. 1, 2020

$\tan$ at No. 128. ADD received some awards in 2009 in the categories of "Best Innovation in Marketing," and "Best Experiential in Marketing." Moreover, it won some more awards in the categories of "Best in Social Marketing," and "Best Experiential Marketing” from the Indonesian Marketing Bulletin. delays still existed and could not be cut short. Then, the delays increased the production and period costs, which decreased ADD's profits.

\section{The SCM of ADD}

This section begins by describing the flow of ADD's supply chain management,

Table 1. ADD Sales Volume (Normadhi et al.)

\begin{tabular}{lll}
\hline Year's & Total Sales & Profits \\
\hline 2014 & $25,850,049,749.45$ & $5,084,979,675$ \\
\hline 2015 & $26,290,693,620.27$ & $4,238,022,820$ \\
\hline 2016 & $28,340,260,936.64$ & $4,808,638,245$ \\
\hline
\end{tabular}

ADD is categorized as an SME under Indonesian regulations because its total revenues are more than 4.8 billion IDR or 3 million USD. It has total revenues of about 28 billion IDR or approximately 2.1 million USD annually. In the Republic of Indonesia's Decree Number 20 of 2008, the sixth article categorizes ADD as an SME. However, ADD has experienced a decline in its profits, probably because of the problem it has with its SCM; which caused $39.08 \%$ of its orders to suffer production delays in 2016. If these delays had not occurred, ADD's profits would have been over 5.5 billion IDR.

This study takes ADD as a typical case; it experienced a decline in profits due to imperfections in the knowledge transformation in its internal departments. This case argues that the main problem with ADD's SCM is in the knowledge transformation from the marketing department to the production department, because the marketing department does not pass on all the details in the sales orders. Therefore, production managers frequently re-demand items to ensure they have all the raw materials and resources to fulfill a particular sales order. This company uses a model to predict market demand, but the after which this study depicts the project's scope and objectives. ADD should control its supply chain optimally. It means that ADD should be concerned about the flow of all the materials, information, and financial matters from and to the related networks both internally and externally. Notably, knowledge of the transformation process must be available, so there are no defects or faults. Figure 1 describes all the flows.

Figure 1 explains the flow of ADD's supply chain management. This article shows potential problems immersing in ADD's SCM. All the potential problems may cause delays to, or even postpone, production, and thus prevent orders being met. This study takes into account how, since the SCM is process-oriented, it supports both the postponement of, or delays to, the customers' orders. This is described and explained as follows.

The lack of internal communication and coordination probably helps to develop production problems for ADD. The lacks are sometimes defective from the marketing department into production. The defection occurs because the information sent from the marketing department is in a brief document, without details of the material requi- 


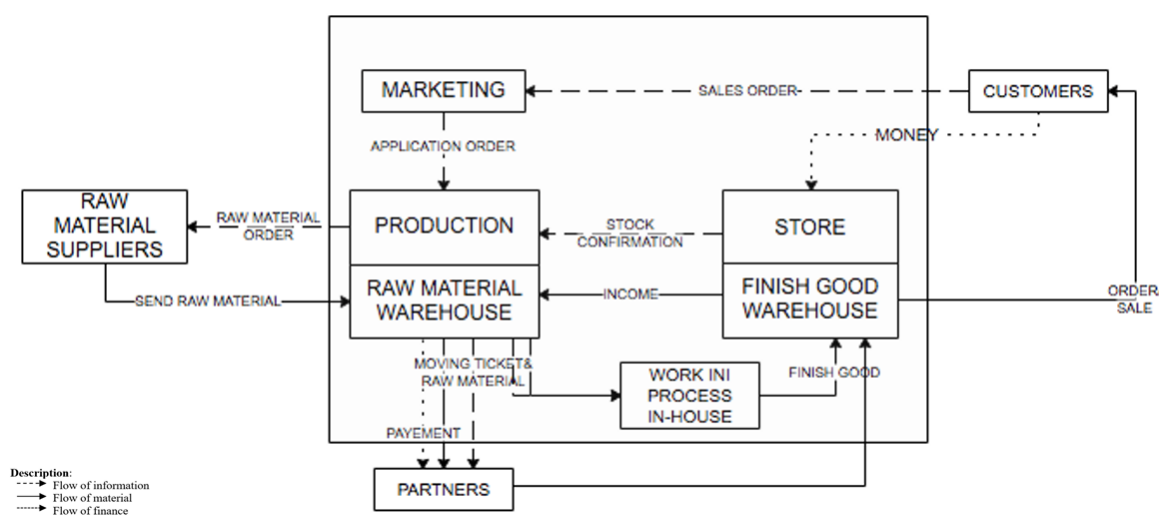

Figure 1. ADD's Supply Chain

sitions or the overhead charges. Production managers have difficulties in understanding these sales orders. They should detail the sales order, but this process needs a lot of time. Moreover, the detailing process is sometimes incorrect because of meetings held among the various departments. Therefore, production managers frequently re-demand all the items they need to ensure they can meet and fulfill a particular sales order. Delays in production then can occur, so the orders cannot be filled on time. This meant that the sales orders get postponed or canceled. Table 2 shows the affected sales orders.

This study takes into account that ADD faces questionable activities that are due to its lack of knowledge about SCM. This problem is due to the weaknesses in the knowledge

Table 2. Sale Order Postponements

\begin{tabular}{|c|c|c|c|}
\hline $\mathbf{P O}$ & Deadline & Finish & LATE \\
\hline 135/Dgd/01/16 & Feb 1 & Feb 12 & 11 \\
\hline 032/Dgd/01/16 & $\operatorname{Jan} 10$ & $\operatorname{Jan} 22$ & 12 \\
\hline $155 / \mathrm{Dgd} / 02 / 16$ & Feb 29 & Mar 11 & 12 \\
\hline 157/Dgd/02/16 & Feb 29 & Mar 10 & 11 \\
\hline 054/Dgd/03/16 & Mar 10 & Mar 22 & 12 \\
\hline 060/Dgd/04/16 & Apr 16 & Apr 30 & 14 \\
\hline 065/Dgd/04/16 & Apr 17 & Apr 29 & 12 \\
\hline 069/Dgd/04/16 & Apr 16 & Apr 29 & 13 \\
\hline 045/Dgd/07/16 & Jul 25 & Augs 7 & 12 \\
\hline 048/Dgd/07/16 & Jul 27 & Augs 11 & 15 \\
\hline 049/Dgd/08/16 & Aug 15 & Aug 29 & 14 \\
\hline 076/Dgd/08/16 & Aug 23 & Sept 4 & 11 \\
\hline 033/Dgd/09/16 & Sep 13 & Sep 25 & 12 \\
\hline 081/Dgd/09/16 & Sep 28 & Oct 09 & 11 \\
\hline 085/Dgd/09/16 & Sept 29 & Sept 9 & 10 \\
\hline 004/Dgd/10/16 & Oct 06 & Oct 18 & 12 \\
\hline 028/Dgd/11/16 & Nov 08 & Nov20 & 12 \\
\hline
\end{tabular}


of the transformation process in its organization, which eventually causes the production delays. This case argues that ADD and its SCM problem is a leading case. We found that $\mathrm{ADD}$ is regarded as a big SME in Indonesia. Moreover, ADD could become a center of learning for other SMEs in the future. In other words, if ADD could improve the knowledge of the transformation process in its internal organization, it could transfer information between its divisions more efficiently and beneficially. Then, it could operate more efficiently.

\section{Case Study Research Method}

This research chose to use an exploratory case study to understand the faults, flaws, or problems with ADD's SCM. This study used this method because it has functions to identify how ADD's SCM works and why the production delays/postponements occurred. This article questioned ADD's CEO and senior managers and observed all the different stages of activity and the information, resources, and financial flows. It means that this study focused on the SCM's processes. This study also focused on elaborating on the SCM defects in the current situation and how they caused the delays to, or postponement of, production and the completion of sales orders, and their inter-relationships. In other words, this study emphasizes the contextual and comprehensive analyses of the fault (Cooper and Schindler, 2011; Eisenhardt and Martin, 2000; Singleton, 1988). This research was performed in four stages, which were: collecting the data, analyzing the data, synthesizing the case output, reporting the results (Eisenhardt and Martin, 2000; Singleton, 1988; Yin, 2009).

This study collected its data from an indepth interview. It chose an in-depth inter- view method because this method can gather detailed information from the selected individual, who should be chosen for his/her great experience and knowledge. This study posits Pavitra, Rajen, and Jyotsna (2014) and Goulding (2002), by explaining that in-depth interviews support the relevance of the collected data. It had an impact on this study by allowing it to filter the abundant data into the most relevant, and discarding the rest (Goulding, 2002; Hague and Jackson, 1987). Furthermore, this study took advantage of the possibility to clarify information and facts face-to-face with the interviewee. It means that whenever this study was unsure about some of the information, the points in question could be raised with the interviewee, who hopefully clarified them.

This study performed six face-to-face interviews with the managers of the marketing, human resources, production planning, and inventory control departments, and the head of purchasing and the head of accounting. We then interviewed 12 junior managers or members of staff, chosen at random. Each interview lasted for about 60 to 95 minutes. The 12 follow-on interviews were to get more information or to clarify points raised previously. All respondents are relatively men, while 25 percent are female. We took note that almost all of the senior managers are graduates from management disciplines while the junior managers and staff are high school graduates. The interview process stopped when all the points raised and data from the SNT and the knowledge of the transformation process had been clarified and no freesh information could be obtained.

The authors played an important role in identifying and analyzing the process of the interviews. This process searched for the answers until the interviewees disclosed 
their experience and knowledge in as much detail as possible. The interviewer focused on clarifying any confusion. It means that the interviewer did not perform an interception or control any divergence from the data collection's objectives. The interviewer applied angulations to two or more of the interviewees. These angulations were used to avoid personal bias both from the interviewer and interviewee. Notably, all the authors consulted each other to prepare a comprehensive understanding of every theme.

In the analysis process, this study posits Strauss, Corbin, and Corbin (1998) and Pavitra et al., (2014). However, it only selected an axial coding because it had prepared the material handout fixed by the SNT and the knowledge of the transformation process. Otherwise, this study neglected open and selective codings. Therefore, this research used the paradigm model to construct the categories formed. Strauss et al., (1998) suggested using this paradigm model. This model arranges phenomenon, causal conditions, context, intervening conditions, action/ interactional strategies, and consequences (Pavitra et al., 2014; Strauss et al., 1998).

\section{Lessons Learned}

This study presents the lessons learned from all phases of the case. It is classified into two different perspectives as follows: the social network theory (SNT) and the knowledge of the transformation process. It used six dimensions of SNT to construct the lessons learned. They are the dissemination or sharing of information, communication, collaboration and innovation, knowledge management, training and learning, and management activities and problem-solving. Meanwhile, this study takes into account the knowledge of the transformation pro- cess, which differs in its perspective between "perfect" and "imperfect." The imperfection completely fashions the lessons learned.

\section{Information dissemination or sharing}

This section investigates ADD's information dissemination/sharing externally and internally. The first discussion is about external sharing. ADD's CEO had disseminated information to all the consumers through social media such as Instagram, watch, Twitter, Facebook, and various websites. The use of social media can help with marketing; it allows potential customers to search for and buy ADD's products via social media. We value that ADD conducts information dissemination/sharing with its customers and suppliers optimally. We infer that ADD has used social media not only for selling its products but also for maintaining its customers. Moreover, ADD has benefited both organizationally and individually. This case showed an excerpt from the information collected without further dissemination.

"We, ADD, have a website. On this website, we uploaded all of our products. Thus, most customers can buy without going to our outlets. They could choose what they want, and they can pay later. It means that we have made things easy for our customers. We also used IG (Instagram), that you can check. This is one of the many social media that we use to brand our products." (IF1-14)

"I made a purchase order and sent it to the suppliers. I made this purchase order by calculating what was needed based on a sales order from the marketing division. To complete this purchase order, I signed it, and I asked my manager to approve it by signing it. Then I scanned and uploaded it into the information system. This process is all manual. I sent the 
Gadjah Mada International Journal of Business - Jan.-April, Vol. 22, No. 1, 2020

purchase order to the suppliers who stocked that specification of fabric. After receiving the fabric, I confirmed this invoice and the supplier's bill of lading by phone." (IF4-5)

The use of social media benefits the customers but creates problems for some partners and suppliers (those involved with sewing and printing). This study notes that ADD works with 20 different sewing and printing partners and material suppliers. The relationship with the material supplier is excellent. However, the relationship with their sewing partners is somewhat fractional and strained. It is because ADD only sends production orders to its sewing and printing partners, together with the necessary raw materials and supporting information once ADD receives an order. Because the sewing and printing partners only receive the disseminated information from ADD when ADD wants them to make something, this infers that ADD did not share the information previously, and consequently the sewing and printing partners do not have enough time to plan their production processes properly, especially with regard to them recruiting the workers they need to meet the order from ADD.

We underline that ADD is not fully aware of the role of information dissemination/sharing. ADD's CEO should increase the awareness linkage by improving the performance of the supply chains (Ganesh, Raghunathan, and Rajendran, 2014; Lee and Whang, 2000; Nadia and Peter, 2017). It is, therefore, crucial to understand that information dissemination/ sharing influences productivity (Cheng, 2017). ADD needs clear information-sharing policies and a proactive approach to information sharing with its production partners (Fawcett, Cynthia, Chard, Fawcett, and Magnan, 2011). In other words, ADD's CEO should com- prehend that information dissemination/ sharing is a key driver to reduce information asymmetry with their production partners.

\section{Communication}

The ADD has organized its internal communication system well. Moreover, its external communications are also good, except with its production partners. This study recalls the case of information dissemination/sharing for the sewing and printing partners. ADD's CEO uses social media to communicate with all the suppliers and partners. However, the CEO does not consider the timing of the requests. When he/she sends information to the division, supplier, or partner, they need time to plan and prepare to support the next production run. It means that the production delays and postponements exist because of the poor timing of communications and orders from ADD.

ADD creates communication structures among its individuals and divisions internally and externally. This study values that the structures are good enough to coordinate and control all of ADD's activities. However, ADD did not induce a complement of the structure that is the communication process. The communication process depends on the timing of when the information is sent or disseminated to others. Proper timing improves coordination and control. It means that ADD did partly in its communication process. This study disclosed an excerpt collected from an informant.

"We used IG, and all internal members in ADD could make comments. From this social media platform, we could see and scan what model types the customers demanded. In IG, there are some likers. To share knowledge internally, we developed a website that internal 
users could comment on. Next, all the comments will be discussed with the marketing division in the scheduled meeting." (IF1-15)

"I got information from other divisions. Whenever customers complained about the colors, the fabric's quality, or other things in ADD's outlets, they informed me about the complaints. Then, I had to write a letter and send it to our suppliers. I did this manually. I noted that we did not have an online system." (IF4-17)

ADD has taken into account what Rogers (1986) and Carol, Choon, and Chun (2013) suggested. It creates and shares information to reach a mutual understanding. It, therefore, means that ADD performs either as a divisional or interpersonal communication network. In other words, it is a communication structure. However, for communication structures to work optimally, the timing of messages or information is crucial. ADD's CEO must consider the timing of his/her information dissemination.

\section{Collaboration and innovation}

This section shows that ADD has entered into complex collaborations which are aimed at producing new products. ADD's management conducts a monthly communication forum. The communication forum discusses sales targets and their consequences for the production department. The marketing division accepts sales orders and passes them on to the production department. The production department usually adjusts its production targets to conform with marketing's demands. The production department usually approves and sometimes negotiates a schedule to finish the orders. It has been running well up to now.

ADD's management has a consensus that collaboration has to be conducted face-to-face. It means that ADD has tools to control all the activities. Unfortunately, the communication forum is sometimes delayed because of staffs' disciplines. We also find that some staff are absent, but not that often. However despite these problems, ADD's management tries to collaborate well with the staff. It infers that ADD's management has direct control over production. However, still partly conducted, ADD's management concentrates on its marketing targets and internal production only. This case is identified by three excerpts below.

"All product designs should have been raised in a communication forum. This forum is used to comment on the designs. In this forum, we can see, we can comment that this product is eligible to be displayed or not. Moreover, does this product conform with our brand or not. We say to all members that $A D D$ is different from others, such as the Hirpik and DGD."(IF1-10)

"In this forum, we can see how marketing targets could be adjusted to match the production capacity. Sometimes, we contradict each other. Although we noted that the marketing division will always send high numbers of products, the production division could not always fulfill marketing's demands. It also happens inversely." (IF3-10)

'We could decide the forum's comments. We will send the production team to ascertain that the products would be marketed. Therefore, we knew what ADD's management wants." (IF2-11)

ADD's management posits the suggestion of Colbry, Hurwitz, and Adair (2014) and Shadur and Bamber (1994). Colbry et al., (2014) suggested that collaboration works irrespective of the formal structure, and that it could be between a manager-with-subordinate, subordinate-with-subordinate, or some other permutation. It means that ADD 
Gadjah Mada International Journal of Business - Jan.-April, Vol. 22, No. 1, 2020

needs to make collaborations, both inter-division and with its suppliers and partners. ADD uses collaboration to make innovations linked to its services and products. In other words, ADD's management looks for teamwork and continued sustainability (Andres, Pablo, and Pablo, 2016). This orientation has created a consensus that collaborative efforts create synergy and allow for better outcomes. It has therefore become management's belief that collaborative work provides a stimulus for the development of new practices toward the next innovation. Colbry et al., (2014) suggested that the collaboration theory is how members in an organization work, irrespective of whether the formal structure is between a manager-with-subordinate, subordinate-with-subordinate, or some other permutation.

\section{Knowledge management}

This research could identify that ADD's management is "a structurally decentralized organization," but it is not yet "a human-empowered decentralized one." It occurred because ADD's management has a lack of knowledge about management activities. This study finds that knowledge flows between managers and their subordinates in one direction only. From the contents' perspective, most knowledge flows from the top management to their subordinates. This research highlights that ADD's management has little in the way of a two-way dissemination of knowledge. In other words, ADD's management could not empower their subordinates to get involved in the knowledge repository.

From a behavioral perspective, ADD's staff and executives have personal knowledge. Moreover, they also prefer to acquire knowledge individually; which means that they do not intend to share what they have with other organizational members. Although ADD's management have established some communication forums and use social media as a knowledge repository at the organizational level, the staff and executives are somehow reluctant to share their knowledge organizationally. This case is shown in the excerpt below.

"We have counseling that is directly from top management to the middle and low ones. We recognized that hard-skills knowledge is topdown from the top management. An example, we were trained in how to do human resources recruitment. We were taught all the stages of buman resources recruitment, and how to interview new entrants. This is what we taught to all the ADD management." (IF1-7)

This study finds various problems with the knowledge management in ADD. The first one is the low motivation of the staff and executives to share their knowledge with others in the organization. The second one is the information flows in the form of oneway traffic, mainly from the top management to subordinates. This study infers that these problems contribute to the occurrence of production delays or postponements. Therefore, ADD's management should improve the motivation of the staff and executives to share their the tacit knowledge with the organization (Josep, Josefa, and Jordi, 2011). Furthermore, ADD's management should create an organizational culture that supports all the staffs' awareness of the importance of two-way communication (Josep et al., 2011; Shakerian, Dehnavi, and Shateri, 2016).

\section{Training and learning}

ADD's management had conducted some training, which included hard skills as well as soft skills. The management always 
offered hard skills training for product developments, i.e., Sablon, 3Ds max designs, and so forth. ADD rarely conducted soft skills training. This study finds that ADD's employees required more soft skills training in comparison with hard skills. It also finds that ADD's management conducted training for internal use only. It means that ADD's management did not perform training in triadic settings. This case is disclosed by an excerpt supporting what management did, as below.

"ADD always conducts some training. The training is used to enhance low and middle managements' knowledge. They fit the organizational needs, but the training is for hard skills only. We noted that the soft skills pieces of training are rarely held. Sometimes, we conducted soft skills training, but this was to increase team-building only. Moreover, the needs of knowledge that have natural characteristics are usually conducted in the form of team ormanagement gatherings, recitations, or others." (IF1-7)

This research recommends that ADD should have conducted training systems in triadic settings. It means that the training involved suppliers and customers as if they are part of ADD's management (Rötzmeier-Keuper, Jennifer, Wünderlich, and Schmitz, 2018; Wynstra, Spring, and Schoenherr, 2015). In other words, ADD's management looks to prohibit the dyadic setting, and always arranges the triadic one (Modi, Wiles, and Mishra, 2015; Satu, Pia, and Wesley, 2014; Wynstra et al., 2015). This relationship strategy is used to balance the knowledge among the organization, suppliers, and customers. Moreover, it makes the business processes more dynamic and better prepared for the immersion of innovation. It means that ADD's management conducted knowledge sharing, communication, and collaboration. Moreover, it had the impact that ADD's man- agement had to empower the firm's executives and staff to undertake problem-solving.

\section{Management activities and prob- lem-solving}

ADD's SCM is not yet optimal. The facts show that there are many production delays. It means that this study could highlight that ADD's management did not segregate the duties of the company's departments very well. This study found that the marketing department could order things directly from vendors, without involving the purchasing department. It infers that unexplicit authority exists among the departments. In other words, ADD's management did not delegate departmental problem-solving explicitly. From another perspective, the purchasing department is like a dummy node and only acts when instructed to by another department.

ADD's management should redesign the authority, responsibility, and the primary task for each department. All ADD's departments can perform their job when their authority is explicit (Gubbins and Dooley, 2013; Gupta and Govindarajan, 1986). Their departmental authority, accompanied by other SCM dimensions, creates a more systematical operation (Henneberg, Juani, Peter, Zhizhong, and Stefanos, 2009). It means that ADD's management has control over all the departments (Gubbins and Dooley, 2013). Therefore, all the departments would be in congruence with the organizational goals and objectives.

From another perspective, ADD's management designed all the standard operating procedures and job descriptions. However, the management did not empower all the company executives with them. Consequently, each department is headed by a highly competent and capable person who will lead 
Gadjah Mada International Journal of Business - Jan.-April, Vol. 22, No. 1, 2020

others. In other words, the standard operating procedures and job descriptions are artifacts only. It, therefore, means that ADD's management should empower the administrative staff to be in alignment with all the organizational regulations (Sih, Hanser, and McHugh, 2009). This study concludes that ADD's standard operating procedures and job de- scriptions are the knowledge (Gubbins and Dooley, 2013) that the management should disseminate to all the executives and staff.

This study infers all the problems have been noted in the previous discussion. It, therefore, conceptualizes all the problems in the framework of the social networks, as shown in Figure 2 below.

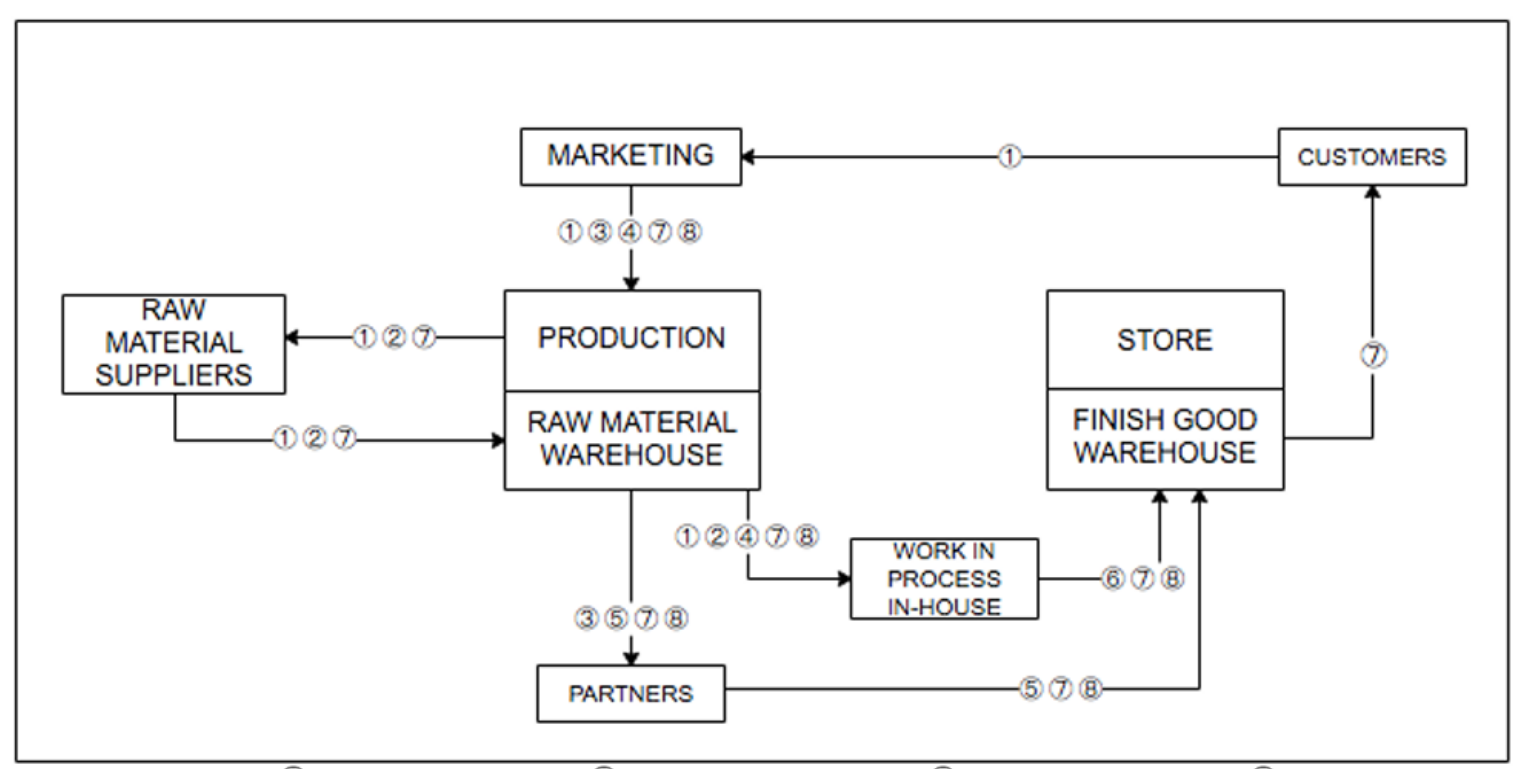

Descriptions: (1)Information Asymmetry; (2)Not Mutual Understanding; (3)Not Collaborative Works; (4)Low

motivation and one-way traffic; (5)Static; (6) No Empowerment; (7)Postponement;

8) Imperfection of the Knowledge of the Transformation Process.

Figure 2. Problems Found in ADD's Social Networks

Figure 2 shows that the imperfection of the knowledge of the transformation process occurred in ADD's own departments. The first dominant problem is the occurrence and existence of information asymmetry, because of its unclear information dissemination between senders and receivers. It is among marketing, production, in-house production, and the storage facility — information asymmetry impacts on the confused communications among the departments. Consequently, the first dominant problem creates the second problem; there is a disassociated understanding between the departments within the organization. Then thirdly, this study pinpoints that uncollaborative work occurred among the departments and staff, especially between marketing and production. The fourth problem is that all the departments have poor motivation. The lowest motivation is in the marketing department, where it is the most powerful one. The low motivation problem, accompanied by the one-way flow of information from the high node, the low one consecutively occurred in command types. Moreover, the absence of face-to-face meetings and communication forums make the process of detailing all the activities worse. This research called the fifth problem is static. The sixth problem is in the training and learning offered both inter- 
nally and externally, but ADD's management cannot improve this very quickly. It is also because of the static. In other words, it infers that there is no empowerment. This study infers that the problems cause the production delays and postponements, which is the seventh problem. Finally, this study constructed all of the problems into a unified concept that is the imperfection of the knowledge of the transformation process. This study noted that there is an eighth problem. For these reasons, this study provides the excerpts below.

"Yesterday, I made an incorrect purchase order. The problem is the order for buying fabric is standardired with a minimum quantity. Consequently, ADD's procurement department could not make a purchase order from supplier 'A' because it was for $250 \mathrm{~kg}$. Although the specification and quantity of the fabrics are the same, the production process for dyeing required a nine-time process. It is due to the dyeing capacity of $240 \mathrm{~kg}$; the dyeing process should be nine-times only. Thus, the purchase order for those fabrics should be added to adjust the production capacity. It is challenging to produce all the finished products at once." (IF4-19)

"There are many errors. It probably is vulnerable to count how much fabric should be ordered from suppliers. Although we have the formula to make a purchase order, it is sometimes wrong. We have some experience, but the errors reoccur." (IF3-24)

"Waiting for the approval is time-consuming. In the applications for purchase and production orders, the approval is too long due to the sequential process from the marketing officer, brand manager, marketing manager, purchasing manager, and operational manager. Then, it is sent to the liaison person to make a purchase order. It takes three days even if the top management are in the office. On the other hand, we are not usually asked to explain the order." (IF2-4)
"While waiting for the authorization and its approval, we can execute the purchase order. It means that the authorization and its approval could be granted later, because it takes seven working days. Meanwbile, the fabric should be processed in the production division immediately. The production of the orders is always late without top management's authorization. Even less, we are asked to use authorization, let alone." (IF3-6)

\section{Knowledge of the Transformation Process}

This study takes note that knowledge of the transformation process in ADD is imperfect. This study highlights that marketing sometimes sends information to production through a short message and WhatsApp only. Moreover, the production manager sends detailed planning documents physically. Both marketing and production managers have sent documents without there being a short discussion about them. It means that among departments, the imperfect knowledge of the transformation process occurs.

This study inspects the behavior of ADD's staff. It found that the team-based structure shows a complete knowledge transformation. However, organizational-based structures show that among divisions and ties could not entirely do. The imperfection of knowledge of the transformation process occurs at the top managerial level. The imperfection also takes place when departments and staff transfer documents without following-up with oral explanations. It means that information asymmetry takes place. Furthermore, this study infers that the top managerial levels at ADD tend to measure and control things using the output approach only; but they do not try to control their subordinates with the behavioral approach. 
This research posits Kirsch, Ko, and Haney (2010), Kirsch (1996) suggested that organizations always improve their organizational- and team-based structures from more complex, nonroutine and knowledge-easy forms into different ones. However, the phenomena above took place, and ADD's management ignores what they have done. It means that ADD's management does not handle the transformation from the knowledge-easy to the different ones. Moreover, the senior management at ADD do not change the structures from the more complex to the more straightforward, and from the nonroutine to the routine. Overall, ADD's management likes to control and measure their subordinates and departments with the output approach, but they should use the behavioral one.

This study, as a consequence of the imperfection of the knowledge of the transformation process, concludes that ADD's management conducted their control with the clan approach only. It infers this because ADD's management faced imperfect knowledge of the transformation process, and a low ability to measure the output (Kirsch, 1996; Ouchi, 1977, 1979). In other words, this study argues that ADD's management does control its subordinates' behavior by using a clan approach. This controlled condition is somehow confusing when ADD faces stiff competition from other companies. It means that ADD's management do not have adaptive competencies, organizationally. It also means that ADD's management never takes into account the behavioral perspective approach to control its subordinates consecutively. Therefore, this research recommends that ADD needs to transform its internal business processes to become a more sustainable SME.

This study suggested a practical or man- agerial implication for the chief officers both in the SME and other corporate firms. To control ones subordinates, officers should use a behavioral approach to ascertain that their messages or commands are received and understood by their subordinates correctly. Moreover, formal or written instructions are not always received by subordinates in a timely manner, although information systems may have been used to distribute them. The top management should use oral communications to comprehend what information has been sent. Furthermore, the behavioral approach and embedded oral communications are also applied to the management of information in the bottom to top officers' relationships.

From another perspective, this study suggested a social implication, especially for informations' dissemination to society. The public principal should use not only formally written messages but also information media that can transform and transmit knowledge to society at large. The public principals should have used information media due to the inability to conduct knowledge transformation through a behavioral approach. It means that they could reduce the distorted information in society. Moreover, public principals could eliminate distorted information, when they repeated knowledge transformations frequently. It means that knowledge transformation could not be done just once.

\section{Conclusion}

This study identifies and analyses ADD's faulty SCM. Furthermore, this study pinpoints what causes this problem in the SCM. This article elaborates on the underlying problem through the social network theory and knowledge of the transformation process. This study uses the framework of six dimensions of the social network theory 
to elaborate on the problem with the SCM. These six dimensions' results yield a holistic problem that ADD's management faces. It is the knowledge of the transformation process.

This study infers that the marketing division does not share information early enough, and consequently the sewing and printing partners do not have enough time to plan their production when they get an order from ADD. The structure is good enough to coordinate and control all ADD's activities, but it did not induce the communication process to function in a timely manner. ADD's management collaborates well with other businesses and has control over its own production. However, still partly conducted, ADD's management concentrates on the firm's marketing targets and internal production. The problem with the knowledge sharing in ADD's is it is just one-way, and goes from the management down to their subordinates. Moreover, this study pinpoints that the knowledge sharing is mostly done via instructions. Another point is that ADD needs to conduct more soft skills training, rather than concentrating on hard skills. The training should not only be internal, but also external in triadic settings. It needs ADD's management to revise and restate what the authority, responsibilities, and the primary task of each department are. Finally, the defect is magnified when oral explanations do not follow document transfers among divisions and the staff. It means that information asymmetry frequently takes place.

ADD's management should optimize its SCM. The most appropriate method to solve this problem is knowledge dissemination among its networks internally and externally. The knowledge of the transformation process should involve all employers and internal departments. At the same time, the external network should also cover the relationship between the management and all the partners and suppliers, as well as the customers. It means that ADD's management chooses to solve the problem with the knowledge of the transformation process. Therefore, it can improve the organizational knowledge that is useful to enhance the staffs' and executives' competencies and capabilities.

This study concludes that ADD's management has a parsimonious solution, which is knowledge of the transformation process. This study suggests the solution of Pandora, where ADD's command went back to the original idea. This solution proposes that ADD's management always improve its organizational- and team-based structures from more complex, nonroutine, and knowledge-easy ones to the other ones. Moreover, the knowledge of the transformation process is not only for the interlinked external networks but also the internal ones. Therefore, ADD's management could control and measure their subordinates and departments by their behavioral and output approaches simultaneously.

\section{Limitations and Future Research}

Although this study is designed using the social network theory and comprehensive knowledge of the transformation process, it has several biases. The first one is inference's validity bias. It was explained that this study identifies and analyzes the problems and causes using the denominators of these theories only. This study opens opportunities that the errors in the sales and production orders could be defined by other perspectives, for example, the level of the staff's competency and capabilities, the degree of the staff's commitment, and so on. 
Gadjah Mada International Journal of Business - Jan.-April, Vol. 22, No. 1, 2020

Second, we did not investigate how ADD's management faces industrial competitiveness. We acknowledged that most SME face operating under increased regulations and laws, especially the tax laws. This study highlights that pressure from all the regulations and laws influence ADD's behavioral adaptations. It means that, somehow, ADD's management usually concentrates on the bonding process. For example, ADD's management conducts tax avoidance and its tax knowledge.

Third, this study had planned the material handouts and schedules for all the in- terviewees. It means that all the interviewees were ready, or they were in a state of high conscientiousness. Otherwise, this study should follow the real activities that executives and staff did daily. It, furthermore, means that this research could not capture when the staff transformed their knowledge into informally. We note that ADD's management sometimes could not conduct the knowledge transformation process through a formal process. ADD's management complemented this transformation by using an informal process to fulfill the optimal one. 


\section{References}

Al-Haddad, A.-H.A.B. (1994). Alawi, risalah adab suluk al-murid: Yaman: Dar Al-Hawi.

Andres, M.D., Pablo, Q.J., and Pablo, F. (2016). Assessing collaboration networks in educational research: A co-authorship-based social network analysis approach. International Journal of Educational Management, 30(3), 416-436. doi: doi:10.1108/IJEM-11-2014-0154

Beatriz, L.d.S.J.A., Alceu, G.A.F., Adriana, B.N.V., and Charbel, J.C.J. (2011). Measuring supply chain management practices. Measuring Business Excellence, 15(2), 18-31. doi: doi:10.1108/13683041111131592

Bloodgood, J.M. (2019). Knowledge acquisition and firm competitiveness: The role of complements and knowledge source. Journal of Knowledge Management, 23(1), 21. doi: https://doi. org/10.1108/JKM-09-2017-0430

Carol, X.O., Choon, L.S., and Chun, K.H. (2013). Computer-mediated communication and social networking tools at work. Information Technology and People, 26(2), 172-190. doi: doi:10.1108/ITP-04-2013-0067

Cheng, H.-H. (2017). The antecedents of creative article diffusion on blogs. Online Information Review, 41(1), 70-84.

Colbry, S., Hurwitz, M., and Adair, R. (2014). Collaboration theory. Journal of Leadership Education. doi: DOI: $10.12806 / V 13 / \mathrm{I} 4 / \mathrm{C} 8$

Cooper, D.R., and Schindler, P.S. (2011). Business research methods: McGraw-Hill/Irwin.

Eisenhardt, K.M., and Martin, J.A. (2000). Dynamic capabilities: What are they? Strategic Management Journal, 21(10/11), 1105-1121.

Fawcett, S.E., Cynthia, W., Chard, A., Fawcett, A.M., and Magnan, G.M. (2011). Information technology as an enabler of supply chain collaboration: A dynamic- capabilities perspective. Journal of Supply Chain Management, 47(1), 38-59. doi: doi:10.1111/j.1745493X.2010.03213.x

Ganesh, M., Raghunathan, S., and Rajendran, C. (2014). The value of information sharing in a multi-product, multi-level supply chain: Impact of product substitution, demand correlation, and partial information sharing. Decis. Support Syst., 58, 79-94. doi: 10.1016/j. dss.2013.01.012

Goulding, C. (2002). Grounded theory: A practical guide for management, business and market researchers: SAGE Publications.

Gubbins, C., and Dooley, L. (2013). Exploring social network dynamics driving knowledge management for innovation. Journal of Management Inquiry, 23(2), 162-185. doi: $10.1177 / 1056492613499203$

Gupta, A.K., and Govindarajan, V. (1986). Resource sharing among sbus: Strategic antecedents and administrative implications. The Academy of Management Journal, 29(4), 695-714. doi: $10.2307 / 255940$

Hague, P.N., and Jackson, P. (1987). Do your own market research: Kogan Page.

Henneberg, S.C., Juani, S., Peter, N., Zhizhong, J., and Stefanos, M. (2009). Mobilizing ideas in knowledge networks: A social network analysis of the human resource management community 1990-2005. The Learning Organization, 16(6), 443-459. doi: doi:10.1108/09696470910993927 
Gadjah Mada International Journal of Business - Jan.-April, Vol. 22, No. 1, 2020

Hosmer, L.T. (1995). Trust: The connecting link between organizational theory and philosophical ethics. Academy of management Review, 20(2), 379-403.

Josep, C.V., Josefa, M., and Jordi, C. (2011). A social network-based organizational model for improving knowledge management in supply chains. Supply Chain Management: An International Journal, 16(4), 284-293. doi: doi:10.1108/13598541111139099

Kirsch, L.J. (1996). The management of complex tasks in organizations: Controlling the systems development process. Organization Science, 7(1), 1-21. doi: 10.1287/orsc.7.1.1

Kirsch, L.J., Ko, D.-G., and Haney, M.H. (2010). Investigating the antecedents of team-based clan control: Adding social capital as a predictor. Organization Science, 21(2), 469-489.

Kwon, I.-W.G., Kim, S.-H., and Martin, D.G. (2016). Healthcare supply chain management; strategic areas for quality and financial improvement. Technological Forecasting and Social Change, 113, 422-428. doi: https://doi.org/10.1016/j.techfore.2016.07.014

Lee, H.L., and Whang, S. (2000). Information sharing in a supply chain. International Journal of Manufacturing Technology and Management, 1(1), 79-93. doi: 10.1504/ijmtm.2000.001329

Levallet, N., and Chan, Y.E. (2019). Organizational knowledge retention and knowledge loss. Journal of Knowledge Management, 23(1), 176-199. doi: 10.1108/jkm-08-2017-0358

Mitchell, J.C. (1974). Social networks. Annual Review of Anthropology, 3(1), 279-299. doi: 10.1146/ annurev.an.03.100174.001431

Modi, S.B., Wiles, M.A., and Mishra, S. (2015). Shareholder value implications of service failures in triads: The case of customer information security breaches. Journal of Operations Management, 35, 21-39. doi: https://doi.org/10.1016/j.jom.2014.10.003

Nadia, Z., and Peter, T. (2017). An information sharing theory perspective on willingness to share information in supply chains. The International Journal of Logistics Management, 28(2), 417-443. doi: doi:10.1108/IJLM-09-2015-0158

Normadhi, N.B.A., Shuib, L., Nasir, H.N.M., Bimba, A., Idris, N., and Balakrishnan, V. (2019). Identification of personal traits in adaptive learning environment: Systematic literature review. Computers and Education, 130, 168-190.

Ouchi, W.G. (1977). The relationship between organizational structure and organizational control. Administrative Science Quarterly, 22(1), 95-113. doi: 10.2307/2391748

Ouchi, W.G. (1979). A conceptual framework for the design of organizational control mechanisms. Management Science, 25(9), 833.

Pavitra, M., Rajen, G., and Jyotsna, B. (2014). Grounded theory research: Exploring work-family enrichment in an emerging economy. Qualitative Research Journal, 14(3), 289-306. doi: doi:10.1108/QRJ-01-2013-0001

Rogers, C.R. (1986). The rust workshop: A personal overview. Journal of Humanistic Psychology, 26(3), 23-45. doi: 10.1177/0022167886263003

Rötzmeier-Keuper, J., Jennifer, H., Wünderlich, N.V., and Schmitz, G. (2018). Triadic relationships in the context of services for animal companions. Journal of Business Research, 85(C), 295-303.

Satu, N., Pia, H.-L., and Wesley, J.J. (2014). Absorptive capacity and network orchestration in innovation communities - promoting service innovation. Journal of Business and Industrial Marketing, 29(2), 173-184. doi: doi:10.1108/JBIM-08-2013-0167

Shadur, M.A., and Bamber, G.J. (1994). Toward lean management? International transferability 
of japanese management strategies to australia. The International Executive, 36(3), 343-364. doi: doi:10.1002/tie.5060360307

Shakerian, H., Dehnavi, H.D., and Shateri, F. (2016). A framework for the implementation of knowledge management in supply chain management. Procedia - Social and Behavioral Sciences, 230, 176-183. doi: https://doi.org/10.1016/j.sbspro.2016.09.022

Sih, A., Hanser, S.F., and McHugh, K.A. (2009). Social network theory: New insights and issues for behavioral ecologists. Behavioral Ecology and Sociobiology, 63(7), 975-988. doi: 10.1007/ s00265-009-0725-6

Singleton, R. (1988). Approaches to social research: Oxford University Press.

Strauss, A., Corbin, J.M., and Corbin, J. (1998). Basics of qualitative research: Techniques and procedures for developing grounded theory: SAGE Publications.

Turban, E., Bolloju, N., and Liang, T.-P. (2010). Social commerce: An e-commerce perspective. Paper presented at the Proceedings of the 12th International Conference on Electronic Commerce: Roadmap for the Future of Electronic Business, Honolulu, Hawaii, USA.

Wasserman, S., and Faust, K. (1994). Social network analysis: Methods and applications. Cambridge: Cambridge University Press.

Wieland, A., Handfield, R.B., and Durach, C.F. (2016). Mapping the landscape of future research themes in supply chain management. Journal of Business Logistics, 37(3), 205-212. doi: $10.1111 /$ jbl.12131

Wynstra, F., Spring, M., and Schoenherr, T. (2015). Service triads: A research agenda for buyersupplier-customer triads in business services. Journal of Operations Management, 35, 1-20.

Yin, R.K. (2009). Case study research: Design and methods: SAGE Publications. 